\title{
ChitoHem hemostatic powder compared with electro- cautery anorectal surgery: A randomized controlled trial
}

\author{
Rezvan Mirzaei ${ }^{1}$, Bahar Mahjoobi ${ }^{* 1}$, Soheila S Kordestani ${ }^{2,3 *}$, Farzaneh NayebHabib ${ }^{3}$ and Saman Mohammadi pour ${ }^{1}$ \\ ${ }^{1}$ Colorectal Center, Iran University of medical science, Tehran, Iran \\ ${ }^{2}$ Medical Engineering Department, Amirkabir University of Technology, Tehran, Iran \\ ${ }^{3}$ ChitoTech Company, Khaghani Building, Somayeh Avenue, Tehran, Iran
}

\begin{abstract}
Purpose: To assess the effect of using a topical hemostatic powder to prevent bleeding in small vessels versus the use of cautery in anorectal surgery.

Methods: In an observer-blinded randomized clinical trial, 60 patients were randomly assigned to two treatment groups and received either ChitoHem hemostatic powder or cautery. Blood coagulation time, physician's satisfaction, postoperative pain, and patient's comfort were evaluated by the visual analog scale.

Results: The mean value of blood coagulation time was significantly lower in the cautery group compared to the ChitoHem group ( $<<0.001$ ). Physician's satisfaction and patient's comfort were significantly increased in the ChitoHem group versus cautery group. The mean pain score significantly decreased in ChitoHem group verses and cautery group. $(\mathrm{p}<0.001)$.

Conclusion: Findings of the present study demonstrated that although blood coagulation time was shorter in cautery compared to ChitoHem, however, pain improvement and both physicians and patients' satisfaction in ChitoHem users were significantly higher. Therefore the use of ChitoHem hemostatic powder is a non-invasive, convenient and repeatable and significantly pain free method.
\end{abstract}

\section{Introduction}

Anorectal surgery is one of the most frequent operations performed today [1] for hemorrhoid, fistula, or fissure. It can be performed in an outpatient or inpatient setting. The blood supply and innervation of the anorectal area is very rich; therefore, the manipulation of this area is very painful and results in rather heavy bleeding; hence, due to the sensitive nature of this area, it is recommended to use other methods. Methods such as ligasure, cautery, sono seizure or laser probes are used in anorectal surgery. There are different brands of chemical substances such as powders, gels, or liquids, on the market [2]. Laparoscopy is a common approach selected in most large colorectal disorders for patients who require surgery [3]. One of the primary goals in the management of surgery is bleeding control during and after the procedure. Bleeding control can be performed in two ways using chemicals or ligation. Ligation is a physical method and no chemical reaction takes place [4]. Various methods such as cautery, fistula surgery, and hemostatic agents can be used for bleeding control during the operation. Efforts to achieve new methods to control bleeding resulting from surgical operations are a continuing challenge. It should be noted that electronic devices like cautery burn the tissue and wound healing is slow; therefore, these patients have more pain than the users of hemostatic agents [5-7]. The use of hemostatic agents can decrease the patient visit rate and post-surgical analgesic use by the patient when compared to cautery [8].

Hemostatic agents are popular means for reducing postoperative bleeding. ChitoHem is a sterile, absorbable hemostatic powder containing oxidized regenerated cellulose which can be used in all types of bleeding, particularly arterial bleeding. The ChitoHem haemostatic powder is directly poured over the surface of bleeding by an applicator.
The surface is completely covered and the bleeding stops within two minutes upon slight pressure by sterile gauze. Hence, attention has been paid to the development of alternative methods to control bleeding, including topical hemostatic dressings [2]. The aim of the present study was to evaluate the effect of the administration of a hemostatic powder agent to prevent bleeding in small vessels in comparison with cautery in anorectal surgery.

\section{Methods and materials}

The present single-blind, randomized, controlled clinical trial was carried out in Hazrat Rasool Hospital, Iran University of Medical Sciences, from May 2015 to December 2015. In total, 60 cases were selected from patients that were admitted to the hospital for rectal surgery. After explaining the study procedure to the patients and confirming the presence of the inclusion criteria, the patients signed written consent forms. The patients were divided into 2 study groups and in each subgroup, the patients were randomly assigned to one of the treatment groups and received either ChitoHem or cautery. Study

Correspondence to: Soheila S. Kordestani, ${ }^{2}$ Medical Engineering Department, Amirkabir University of Technology, Tehran, Iran

${ }^{3}$ ChitoTech Company, Khaghani Building, Somayeh Avenue, Tehran, Iran.

Bahar Mahjoubi, Colorectal Research Center, Iran University of medical science, Tehran, Iran; Email: liamoh@gmail.com

Key words: anorectal surgery, bleeding, cautery, hemostatic powder, ChitoHem

Received: November 20, 2016; Accepted: December 19, 2016; Published: December 23, 2016 
groups included those who had fistula surgery, had bleeding from vessels with a diameter of $2-3 \mathrm{~mm}$, were between $30-60$ years old, and signed informed consent form. Treatment allocation was performed by one of the researchers who were unaware of the data obtained during the study. After treatment, pain, patient's comfort, physician's satisfaction and postoperative adverse effects were measured in both groups. Postoperative pain and patient's comfort were evaluated using the visual analog scale that was explained to patients. Pain was evaluated with a score of 0 (no pain) to 10 (worst pain possible). Patients were asked to rate their pain initially in the recovery and then in the ward (after recovery) in both groups postoperatively. The coagulation time was measured in both groups after using the treatments.

\section{Data collection tool}

A separate checklist was developed to collect the patients' demographic data, including age (years), sex (male or female), clinical data (type of bleeding, type of haemostatic method), that were extracted from the patients' files. The visual analogue scale (VAS) was used for the assessment of variations in the intensity of pain [9] and patient comfort [10].

The protocol was approved by the Ethics Committee of Iran University of Medical Sciences.Written informed consent was taken from all participants. Participants could leave the study if they so wished. Moreover, the subjects were assured that leaving the study or non-participation did not affect the treatment procedure.

\section{Data analysis}

The primary end point in each sub-study group was blood coagulation time and the secondary end points were the physician's satisfaction, patient's comfort, postoperative complications, intraoperative rebreeding, and postoperative pain. The sample size provided a greater than $90 \%$ power ( 2 -tailed t test, $\mathrm{P}<0.05$ significance level to detect a $60 \%$ reduction in blood coagulation between pooled ChitoHem or cautery). On the basis of the observed incidence of blood coagulation time in the ChitoHem group, the study power was slightly greater than predicted.

The data of all patients who were assessed at the beginning of the study was analysed using SPSS-18. Paired t-test was used to estimate the significance of the differences between the two groups. Data (pain) was analyzed using a repeated-measures analysis of variance (ANOVA) with a single independent primary factor of postoperative time (recovery and hospitalized). Significant main effects $(\alpha=0.05)$ were followed by contrasts to identify differences.

\section{Results}

Between May 2015 and December 2015, 60 patients were included in the trial. There were 26 men and 4 women in the cautery group and 21 men and 7 women in the ChitoHem group with a median age of 39.23 years in the cautery and 43.73 years in the ChitoHem group. These patients had anorectal surgery. Table 1 shows the mean and SD of all variables between two treatment groups. Statistically significant differences were found between the two groups.

Overall, we found differences in the rate of physician satisfaction, pain, and patient comfort between the two groups; however, in ChitoHem recipients, the mean pain score was lower in comparison with the patients in the cautery group ( 3 vs. 5 respectively; $\mathrm{P}<0.001$ ).

The mean difference of blood coagulation time significantly increased by 0.63 (CI 95\%: $0.34-0.91$ ) in the cautery versus the ChitoHem group.

Physician satisfaction and patient comfort significantly increased by 0.63 (CI 95\% 0.34- 0.91) and 0.26 (CI 95\% 0.04- 0.48) and 2.66 (CI 95\% 2.48-2.84) in the ChitoHem group when compared to the cautery group. The mean difference of pain significantly decreased by -2.50 (CI 95\%: -3.14- -1.85) from ChitoHem compared to cautery. A postoperative chronic wound was observed in the cautery group.

Pain changes are demonstrated in Table 2 . The primary changes of pain in the recovery and the subsequent pain changes in the ward (after recovery) were not significant in each group. As shown in Figure 1 , the mean pain was significantly different between the two groups at recovery and hospitalized whereas the pain mean changes were not statistically significant within each group.

\section{Discussions}

ChitoHem is a topical hemostatic powder with a superabsorbent nature; therefore, it accelerates the onset of clotting when used intraoperatively in the bleeding site. On the other hand, our randomised controlled clinical trial showed that the ChitoHem was more effective in reducing postoperative pain in comparison with cautery. Based on the previous findings, the efficacy of ChitoHem has been demonstrated as a topical hemostatic agent, to be used intraoperatively on the bleeding site [11].

Previous studies showed similar effects of ChitoHem when compared with the control group [12]. These results are comparable with those reported by prospective trials of other topical hemostatic agents, including the trials of CELOX, HemCon, and Quikclot [2]. It

Table 1. Mean differences between two treatment groups variables.

\begin{tabular}{|c|c|c|c|c|c|}
\hline Variables & ChitoHem & cautery & Paired Differences & & \\
\hline & & & Mean (SD) & $95 \%$ CI & Sig. (2-tailed) \\
\hline Blood coagulation time & $1.63(.76)$ & $1.00(.00)$ & $.63(.76)$ & {$[.34, .91]$} & $<0.001^{*}$ \\
\hline $\begin{array}{l}\text { mean difference of pain between treatment groups } \\
\text { at recovery }\end{array}$ & $3.13(1.54)$ & $5.27(1.89)$ & $-2.13(2.08)$ & {$[-2.91,-1.35]$} & $<0.001 *$ \\
\hline $\begin{array}{l}\text { mean difference of pain between treatment groups } \\
\text { after recovery }\end{array}$ & $3.00(1.23)$ & $5.50(1.50)$ & $-2.50(1.73)$ & {$[-3.14,-1.85]$} & $<0.001^{*}$ \\
\hline Physician's satisfaction & $8.93(.25)$ & $8.67(.47)$ & $.26(.58)$ & {$[.04, .48]$} & $.018^{*}$ \\
\hline Patient's comfort & $9.67(.47)$ & $7(0)$ & $2.66(.47)$ & {$[2.48,2.84]$} & $<0.001 *$ \\
\hline
\end{tabular}

Table 2. Mean pain changes in treatment groups with ChitoHem and cautery in recovery and hospitalized.

\begin{tabular}{|l|c|c|}
\hline Measures & $\begin{array}{c}\text { Recovery } \\
\text { Mean (SD) }\end{array}$ & $\begin{array}{c}\text { Hospitalized } \\
\text { Mean (SD) }\end{array}$ \\
\hline ChitoHem treatment group & $3.13(1.54)$ & $3.00(1.23)$ \\
\hline Cautery treatment group & $5.27(1.89)$ & .697 \\
\hline
\end{tabular}




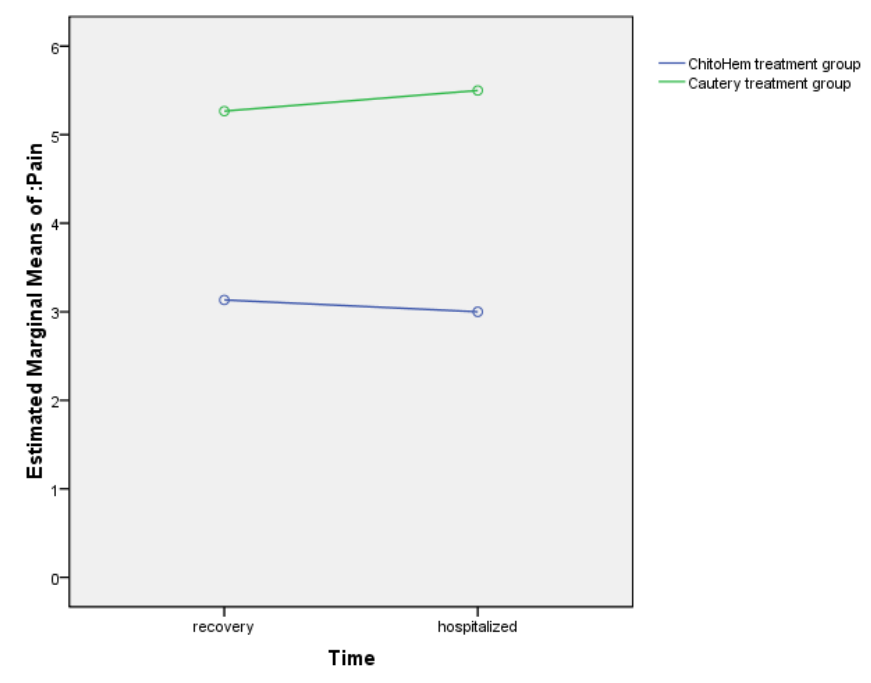

Figure 1. Pain changes measured in the treatment groups at recovery and hospitalized.

seems that ChitoHem is more efficient in pain reduction than other hemostatic agents. No adverse effects were observed. The safety of ChitoHem has also been tested in patients undergoing diagnostic coronary angiography [12]. Time to achieve hemostasis was significantly lower in the cautery group compared to the ChitoHem group. However, the advantages of ChitoHem powder were that:

- There is no need for re-operation.

- The use of ChitoHem is completely non-invasive.

- $\quad$ It is easy to use and does not require special equipment.

- $\quad$ It is not painful.

- It is available for home use (during dressing change)

- It is reproducible (i.e. it does not damage the patient's tissue and can be used several times in several bleeding episodes)

\section{Conclusion}

The findings of the study were consistent with results of prior researches; blood coagulation time was significantly lower in the cautery compared to the ChitoHem group. However, the improvements in pain, physician's satisfaction, and patient's comfort were important findings of the present study. Moreover, it should be noted that ChitoHem causes minimal surrounding tissue damage during the operation when compared with cautery.

\section{References}

1. Weiser TG, Regenbogen SE, Thompson KD, Haynes AB, Lipsitz SR, et al. (2008) An estimation of the global volume of surgery: a modelling strategy based on available data. Lancet 372: 139-144. [Crossref]

2. Kozen BG, Kircher SJ, Henao J, Godinez FS, Johnson AS. An alternative hemostatic dressing: comparison of CELOX, HemCon, and QuikClot. Academic Emergency Medicine 15:74-81.

3. Remzi FH, Kirat HT, Kaouk JH, Geisler DP (2008) Single-port laparoscopy in colorectal surgery. Colorectal Dis 10: 823-826. [Crossref]

4. Lo GH, Lai KH, Cheng JS, Chen MH, Chiang HT (2001) A prospective, randomized trial of butyl cyanoacrylate injection versus band ligation in the management of bleeding gastric varices. Hepatology 33: 1060-1064. [Crossref]

5. Armstrong DN, Ambroze WL, Schertzer ME, Orangio GR (2001) Harmonic Scalpel $\mathbb{R}$ vs. electrocautery hemorrhoidectomy: a prospective evaluation. Diseases of the colon \& rectum 44:558-64.

6. Bolliger CT, Sutedja TG, Strausz J, Freitag L (2006) Therapeutic bronchoscopy with immediate effect: laser, electrocautery, argon plasma coagulation and stents. Eur Respir J 27: 1258-1271. [Crossref]

7. Wexner SD, Johansen OB (1992) Laparoscopic bowel resection: advantages and limitations. Ann Med 24: 105-110. [Crossref]

8. Barnard J, Millner R (2009) A review of topical hemostatic agents for use in cardiac surgery. Ann Thorac Surg 88: 1377-1383. [Crossref]

9. Price DD, McGrath PA, Rafii A, Buckingham B (1983) The validation of visual analogue scales as ratio scale measures for chronic and experimental pain. Pain 17: 45-56. [Crossref]

10. Wewers ME, Lowe NK (1990) A critical review of visual analogue scales in the measurement of clinical phenomena. Res Nurs Health 13: 227-236. [Crossref]

11. Nowshad N, Saghafinia M, Panahi F, Bolandparvaz S3, Tanideh N4 (2012) Comparison of the efficacy of two local haemostatic agents. Trauma Mon 16: 188-190. [Crossref]

12. Kordestani SS, Noohi F, Azarnik H, Basiri H, Hashemi M, Abdi S, et al. (2012) A randomized controlled trial on the hemostasis of femoral artery using topical hemostatic agent. Clinical and Applied Thrombosis/Hemostasis 18: 501-505.

Copyright: (C2016 Mirzaei R. This is an open-access article distributed under the terms of the Creative Commons Attribution License, which permits unrestricted use, distribution, and reproduction in any medium, provided the original author and source are credited. 